\title{
Prognostic Value of ADAMTS Proteases and Their Substrates in Epithelial Ovarian Cancer
}

\author{
Maíra Assis Lima ${ }^{a} \quad$ Liliane dos Santos $^{a} \quad$ José Antonio Turri ${ }^{a}$ b Suely Nonogaki ${ }^{c}$ \\ Marcilei Buim $^{c}$ Joema Felipe Limac, e, f João de Jesus Viana Pinheiro ${ }^{d}$ \\ Cynthia Aparecida Bueno de Toledo Osórioc Fernando Augusto Soares ${ }^{c, g}$ \\ Vanessa Morais Freitas ${ }^{a}$ \\ a Department of Cell and Developmental Biology, Biomedical Sciences Institute, and bepartment of Gastroenterology, \\ Faculty of Medicine, University of São Paulo, and ' Department of Anatomical Pathology, A.C. Camargo Cancer Center, \\ São Paulo, and d Department of Oral and Maxillofacial Pathology, School of Dentistry, Federal University of Pará, Belém, Brazil; \\ e Sunnybrook Health Sciences Centre, and ${ }^{\mathrm{f} O n t a r i o ~ I n s t i t u t e ~ o f ~ C a n c e r ~ R e s e a r c h, ~ T o r o n t o, ~ O n t ., ~ C a n a d a ; ~}{ }^{9}$ Department of \\ General Pathology, Dental School, University of São Paulo, São Paulo, Brazil
}

\section{Key Words}

ADAMTS · Ovarian cancer · Proteases · Proteoglycans

\begin{abstract}
Background: ADAMTS are metalloproteases with disintegrin and thrombospondin motifs. They are secreted proteases playing a role in biological processes such as inflammation, angiogenesis, and urogenital development. ADAMTS have specific substrates, such as the proteoglycans (PG) versican, aggrecan, and brevican. Despite data indicating a role of ADAMTS in tumor invasion and metastases, effects played by these molecules in cancer progression are still controversial. In ovarian cancer, the importance of ADAMTS gene mutations was recently described and related to chemotherapy outcome. Objective: To analyze protein levels of ADAMTS-1, -4 , and -5 , and TIMP-3 in human ovarian cancer classified as benign, borderline, or malignant. We also assessed the expression of the ADAMTS substrates aggrecan, brevican, and versican in these neoplasms. Correlations between overall
\end{abstract}

survival and protein expression were performed. Methods: Tumors were classified according to the WHO Classification of Tumors of Female Reproductive Organs. Protein and PG expression was studied by immunohistochemistry. Differences in labeling were analyzed by percent measurements of stained areas. Results: ADAMTS-1, ADAMTS-5, and its tissue inhibitor TIMP-3 are increased in borderline and malignant tumors compared to benign neoplasms. Aggrecan and versican levels were increased in malignant subtypes compared to benign ovarian cancer. Higher ADAMTS-1, TIMP-3, and versican expression was associated with a shorter overall survival. Conclusions: Comparison of protease, TIMP-3, and substrate expression showed that in malignant tumors all ADAMTS and TIMP-3 expression levels were significantly raised compared to the substrates studied.

(C) 2016 S. Karger AG, Basel

Maíra Assis Lima, Liliane dos Santos, and José Antonio Turri contributed equally to this work.

\section{KARGER}

E-Mail karger@karger.com www.karger.com/pat
(C) 2016 S. Karger AG, Basel

$1015-2008 / 16 / 0836-0316 \$ 39.50 / 0$
Vanessa Morais Freitas, $\mathrm{PhD}$

Department of Cell and Developmental Biology, ICB-USP

Av. Prof. Lineu Prestes 1524, Ed Biomédicas 1 sala 428

São Paulo, SP 05508-000 (Brazil)

E-Mail vfreitas@usp.br 


\section{Introduction}

Ovarian cancer is the fifth most common cancer affecting women in the world today, with associated statistics illustrating a steadily increasing rate, particularly in women aged $\geq 65$ years. The World Health Organization Classification of Tumors for ovarian cancer divides these components according to the most likely tissue of origin: epithelial (>90\%), mesenchymal tumors, mixed epithelial and mesenchymal tumors, sex cord-stromal, mixed sex cord-stromal tumors, germ cell, germ cell-sex cord stromal tumors, mesothelial tumors, soft tissue tumors, lymphoid and myeloid tumors, metastases, and miscellaneous. Surface epithelial tumors are further classified by cell type (serous, mucinous, endometrioid, clear cell, Brenner, seromucinous, and undifferentiated). They can be classified as benign, borderline, or malignant according to morphology and proliferation and/or cellular atypia, and differ in biological behavior. According to a dualistic model of epithelial tumors, there are two categories based on genetic alterations with separate pathways: type I shows a high frequency of KRAS and BRAF mutations but no TP53 and type II presents mutations in TP53. Borderline serous tumors/atypical proliferative tumor and low-grade serous cancers demonstrate mutations in KRAS or BRAF and few chromosomal abnormalities. High-grade serous carcinomas harbor mutations in TP53 and are chromosomally highly unstable [1-3].

Extracellular matrix (ECM) components attract increasing interest as determinants in the growth and progression of solid tumors. Extensive remodeling of the normal ECM in tumors can progress via the degradation of preexisting ECM molecules and/or by the neosynthesis of ECM components, which are often not present in the ECM of normal tissues [4]. In ovarian cancer, alterations in the extracellular environment are critical for tumor initiation and progression and intraperitoneal dissemination [5].

ADAMTS (a disintegrin and metalloproteinase with thrombospondin motifs) are a family of secreted zinc-dependent metalloproteinases comprising at least 19 genetically distinct members in humans $[6,7]$. They share homology in the catalytic ADAM metalloprotease and disintegrin domains, but they differ in variable numbers of thrombospondin-like motifs and other carboxyl-terminal domains associated with ECM interaction $[6,8,9]$.

The majority of ADAMTS subtypes have been characterized at the structural level, and their expression is associated with pre- and postnatal growth, and onset and progression of cancer, arthritis, Alzheimer's disease, and a number of inflammatory and thrombotic conditions (table 1 ) $[6,7,10,11]$. Some ADAMTS subtypes, such as ADAMTS-1, -4, -5, -8, -9, and -15, have been subclassified as aggrecanases because of their ability to cleave large chondroitin sulfate that provides the scaffold for ECM organization in a wide array of tissues [10]. Despite their structure similarity to others matrix metalloproteinases, ADAMTS have a narrow substrate specificity [12]. This feature could provide an advantage for ADAMTS inhibitors in the treatment of cancer or other pathologies compared to other proteases.

Proteoglycans (PG) are macromolecules composed of a specific core protein substituted with covalently linked glycosaminoglycans (GAG). Hyaluronic acid (HA) is a GAG synthesized in a free form noncovalently bound to a core protein. GAG are linear, negatively charged polysaccharides comprised of repeating disaccharides of hexosamines ( $\mathrm{N}$-acetyl-galactosamine or $\mathrm{N}$-acetyl-glucosamine) and by uronic acids (D-glucuronic acid or L-iduronic acid) sulfated at various positions [13]. PG are expressed at the cell surface and ECM of all mammalian cells and tissues, playing an important role in cell-cell and cell-matrix interactions and signaling [14]. Hyalectans are a subfamily of PG, including versican, aggrecan, and brevican. These molecules are well-known ADAMTS-1, -4 and -5 substrates [15-18]. Hyalectans have the ability to bind HA through their N-terminal globular domain (G1); the central domain carries most of the GAG chains and exhibits lectin-like activity located in the C-terminal globular domain (G3) $[13,19]$. The endogenous tissue inhibitor of metalloproteinase 3 (TIMP-3) regulates ADAMTS-1, -4 , and -5 proteolytic activity [20-22].

The expression, regulation, and function of ADAMTS and their substrates remain poorly characterized in ovarian cancer to date. In this study, we carried out a comparative analysis of ADAMTS-1, -4 , and -5, and TIMP-3 in human benign, borderline, and malignant ovarian cancer. Expression of the known ADAMTS substrates aggrecan, brevican, and versican was also analyzed in the same neoplasms. Immunohistochemistry was used to assess the presence of all proteins and PG.

\section{Methods}

Tissue Microarray Construction

Patients with ovarian cancer $(n=46)$, diagnosed between 1986 and 2007, were randomly selected from the files of the A.C. Camargo Cancer Center of Sao Paulo, Brazil.

For tissue microarray (TMA) construction, H\&E-stained slides from each paraffin-embedded tumor block were checked to select 
Table 1. ADAMTS-1, -4 and -5 : substrates, physiological and pathological roles

\begin{tabular}{|c|c|c|c|}
\hline Protease & Physiological role & Pathological role & Substrates \\
\hline ADAMTS-1 & $\begin{array}{l}\text { Development and function of the urogenital } \\
\text { system [24] } \\
\text { Normal growth and function of kidneys, } \\
\text { adrenal glands and female reproductive } \\
\text { organs [26] } \\
\text { Normal follicular development and } \\
\text { ovulatory process [28] } \\
\text { Endometrial remodeling and placental } \\
\text { development [32] }\end{array}$ & $\begin{array}{l}\text { ADAMTS } 1 \text { mutations contributed to treatment } \\
\text { outcome in ovarian cancer patients [23] } \\
\text { Decreased ADAMTS } 1 \text { in breast cancer cells } \\
\text { increase migration and invasion [25] } \\
\text { Decreased expression compared to health tissue } \\
\text { in ovarian cancer [9] } \\
\text { Decreased folliculogenesis and ovulation in the } \\
\text { absence of ADAMTS } 1[29,30] \\
\text { Increased in atherosclerosis [33] } \\
\text { Overexpressed in Alzheimer's disease [35] }\end{array}$ & $\begin{array}{l}\text { Aggrecan [17] } \\
\text { Versican [27] } \\
\text { Nidogen-1, } 2 \text { [31] } \\
\text { Thrombospondin-1, } 2 \\
\text { [34] }\end{array}$ \\
\hline ADAMTS-4 & $\begin{array}{l}\text { ECM degradation in cartilage }[37] \\
\text { Expression in periovulatory ovarian } \\
\text { follicules and ovulatory process }[40,41] \\
\text { Neuronal plasticity }[44]\end{array}$ & $\begin{array}{l}\text { Increased in osteoarthritis [38] } \\
\text { Increased in brain tumors [42] } \\
\text { Increased in atherosclerosis [45] } \\
\text { Increased in inflammation [37] }\end{array}$ & $\begin{array}{l}\text { Aggrecan [36] } \\
\text { Versican [27, 39] } \\
\text { Brevican [43] } \\
\text { Matrilin [46] } \\
\text { Biglycan [47, 48] } \\
\text { Decorin [47] }\end{array}$ \\
\hline ADAMTS-5 & $\begin{array}{l}\text { ECM degradation in cartilage [49] } \\
\text { Skeletogenesis [51] } \\
\text { Expressed in the peri-implantation period } \\
\text { in embryo and trophoblast [53] } \\
\text { Ovulatory process and atretic follicles [41] }\end{array}$ & $\begin{array}{l}\text { Increased in osteoarthritis [38] } \\
\text { Increased in brain tumors [42] } \\
\text { Increased in atherosclerosis [45] }\end{array}$ & $\begin{array}{l}\text { Aggrecan [50] } \\
\text { Versican [52] } \\
\text { Brevican [54] } \\
\text { Neurocan }[55] \\
\text { Matrilin }[46,56]\end{array}$ \\
\hline
\end{tabular}

Table 2. Patient characteristics

\begin{tabular}{lrc}
\hline & $n$ & $\begin{array}{l}\text { Age at } \\
\text { diagnosis }\end{array}$ \\
\hline Benign & 9 & 51 years \\
$\quad$ Serous cystadenoma & 4 & $(29-71)$ \\
Mucinous cystadenoma & 2 & \\
Brenner tumor & 2 & \\
Serous cyst & 1 & \\
\hline Borderline & 9 & 36 years \\
Serous tumor & 4 & $(13-57)$ \\
Seromucinous tumor & 3 & \\
Mucinous tumor & 2 & \\
\hline Malignant & 28 & 58 years \\
Low-grade serous carcinoma & 2 & $(31-81)$ \\
Endometrioid carcinoma & 10 & \\
High-grade serous carcinoma & 11 & \\
Malignant mixed Müllerian tumor & & \\
$\quad$ or carcinosarcoma & 1 & \\
Mucinous carcinoma & 1 & \\
Seromucinous tumor & 1 & \\
Clear-cell carcinoma & 1 & \\
Serous carcinoma mixed with & & \\
$\quad$ endometrioid adenocarcinoma & 1 & \\
\hline & & \\
\hline & & \\
\hline
\end{tabular}

a morphologically representative tumor area, which was then selected to construct the TMA paraffin block. In each case, two tissue cylinders with a diameter of $1 \mathrm{~mm}$ were punched out from the marked tumor areas of each of the 46 donor paraffin blocks and distributed into 4 new recipient paraffin blocks using the manual tissue arrayer I (Beecher Instruments, Silver Spring, Md., USA). Sections $(3 \mu \mathrm{m})$ were cut from the TMA paraffin block using the paraffin tape-transfer system (Instrumedics, St. Louis, Mo., USA). One section was stained with H\&E to confirm the presence of the tumor by light microscopy, and standard slides were used for immunohistochemical analyses. Samples were grouped according to morphological tumor criteria; there were 9 benign, 9 borderline, and 28 malignant tumors (table 2).

\section{Immunohistochemistry}

For antigen retrieval, $10 \mathrm{mM}$ of citrate buffer $(\mathrm{pH}$ 6.0) with $0.05 \%$ Tween 20 were applied for $30 \mathrm{~min}$ at $100^{\circ} \mathrm{C}$. Antibodies to ADAMTS-1 (polyclonal, ab28284; Abcam, Cambridge, Mass., USA), ADAMTS-4 (polyclonal, ab84792), ADAMTS-5 (polyclonal, ab39202), TIMP-3 (polyclonal, ab39184), aggrecan (monoclonal, ab3778), brevican (polyclonal, ab67580; all from Abcam), and versican (polyclonal, HPA004726; Sigma-Prestige) were diluted $1: 250,1: 250,1: 250,1: 400,1: 100,1: 100$, and 1:100, respectively. Novolink biotin-free polymer (Leica, New Castle, UK) was used to analyze TMA, and diaminobenzidine (DAB) served as the chromogen. The local ethics committees at the participating institutions approved tissue analyses (CEP-ICB 1017/12 and CEPHospital A.C. Camargo 1467/10). 
Analysis

ImageJ public domain software (http://rsb.info.nih.gov/ij/) was used for image analysis. The DAB channel was separated by the color deconvolution plugin. The stained areas were segmented and measured. Quantification involved DAB labeling intensity of tumor areas. Immunohistochemical staining was quantitatively assessed by three independent observers (M.A.L, L.d.S., and V.M.F.) with minimal interobserver variability $(<5 \%)$.

Survival

Patients were grouped according to protein expression. The total number of patients was divided into two subgroups: patients with high and low levels of the molecules analyzed. The lifetime of each patient was calculated taking the age of first diagnosis of ovarian cancer and the current state into consideration. These data were collected from patient medical records.

\section{Statistical Analysis}

Data were analyzed using GraphPad Prism 5 software (GraphPad Software, Inc., San Diego, Calif., USA). Values are expressed in arbitrary units and were subjected to one- or two-way ANOVA, followed by Bonferroni's multiple comparison test. Survival analysis was carried out by the Kaplan-Meier method and the log-rank test. Prognostic significance was evaluated by Cox regression analysis. Significance was established at $\mathrm{p}<0.05$.

\section{Results}

Benign samples showed intense staining of ADAMTS1 in ovarian surface epithelium and in part of the stroma. Stromal labeling was mostly located in fibroblast nuclei and in scattered ECM areas (fig. 1a). Borderline tumors also showed intense labeling in epithelial tumor cells and stroma (fig. 1b). Malignant tumors exhibited prominent ADAMTS-1 staining in epithelial tumor cells. In stroma, some fibroblasts presented intense labeling and ECM showed a discrete presence of the protease (fig. 1c). ADAMTS- 4 was identified in the ovarian surface epithelium, the adjacent connective tissue (fig. 1d), and in the vessels walls (fig. $1 \mathrm{~d}$; arrowhead). In borderline and malignant tumors, ADAMTS-4 was mostly located in epithelial cells, with discrete stromal staining (fig. 1e, f). In borderline tumors, staining was restricted to the apical region of cells (fig. 1e). In malignant epithelial neoplasms, ADAMTS-4 was present in cell cytoplasm and nuclei (fig. 1f). ADAMTS-5 presented a staining pattern similar to ADAMTS-1 (fig. 1g-i). TIMP-3 was present in the same areas as the proteases studied, mainly epithelial cells (fig. $1 \mathrm{j}-1$ ).

ADAMTS substrate staining patterns are shown in figure 2. Aggrecan was observed mainly in tumor cells (fig. 2a-c). Benign samples showed discrete immunoreaction in the stroma, and epithelial cells showed stronger labeling (fig. 2a). Aggrecan staining was remarkable in the apical region of epithelial tumor cells (fig. 2b) and weak in the tumor stroma of borderline tumors. Malignant samples showed strong staining concentrated in tumor epithelial cells (fig. 2c). Brevican presented weak staining in the epithelium and stroma of all tumors studied (fig. $2 \mathrm{~d}-\mathrm{f}$ ). In benign tumors, versican was mainly found in the vessels walls (fig. $2 \mathrm{~g}$ ). In benign and borderline tumors, staining was generally weak (fig. $2 \mathrm{~g}$, h). In contrast, in ovarian malignant tumors, versican staining appeared more prominent in stroma (fig. 2i).

Quantitative immunohistochemistry is illustrated in figure 3. ADAMTS-1 and -5, and TIMP-3 exhibited a significant increase compared to benign tumors (fig. 3a). ADAMTS-5 and TIMP-3 expression was also significantly higher compared to borderline neoplasms. With regard to substrate expression, aggrecan and versican presented a higher area fraction compared to benign neoplasms (fig. 3a). Expression of proteases, TIMP-3, and substrates in malignant tumors is displayed in figure $3 \mathrm{~b}$. ADAMTS and TIMP-3 staining is twofold higher than aggrecan, brevican, and versican total area staining.

Overall survival of patients with higher ADAMTS-1, TIMP-3, and versican expression was shorter than in patients with weak labeling for these molecules (fig. $4 \mathrm{a}$, d, h). The other PG and proteases studied here did not show statistically significant differences between high- and low-expression groups (fig. 4b, c, e, f).

Additionally, mean overall survival was 94.95 months in patients presenting higher levels of TIMP-3 versus 156.2 months in patients with lower levels of TIMP-3 ( $\mathrm{p}=0.0042$, online suppl. fig. $1 \mathrm{~S}$; for all online suppl. material, see www.karger.com/doi/10.1159/000446244). Patients presenting high versican levels had an average survival of 92.85 months compared to 152 months in patients with low versican expression $(\mathrm{p}=0.0059$, online suppl. fig. 1S). These results corroborate data from overall survival of 1,307 patients. Patients with higher ADAMTS-1, TIMP-3, or versican expression presented lower survival rates (online suppl. fig. 2S).

\section{Discussion}

We observed that ADAMTS- 1 and-5, and its tissue inhibitor, TIMP-3, are increased in borderline and malignant tumors compared to benign neoplasms. We also noted that aggrecan and versican had increased levels in malignant compared to benign ovarian cancer. Overall comparisons of proteases, TIMP-3, and substrates showed 


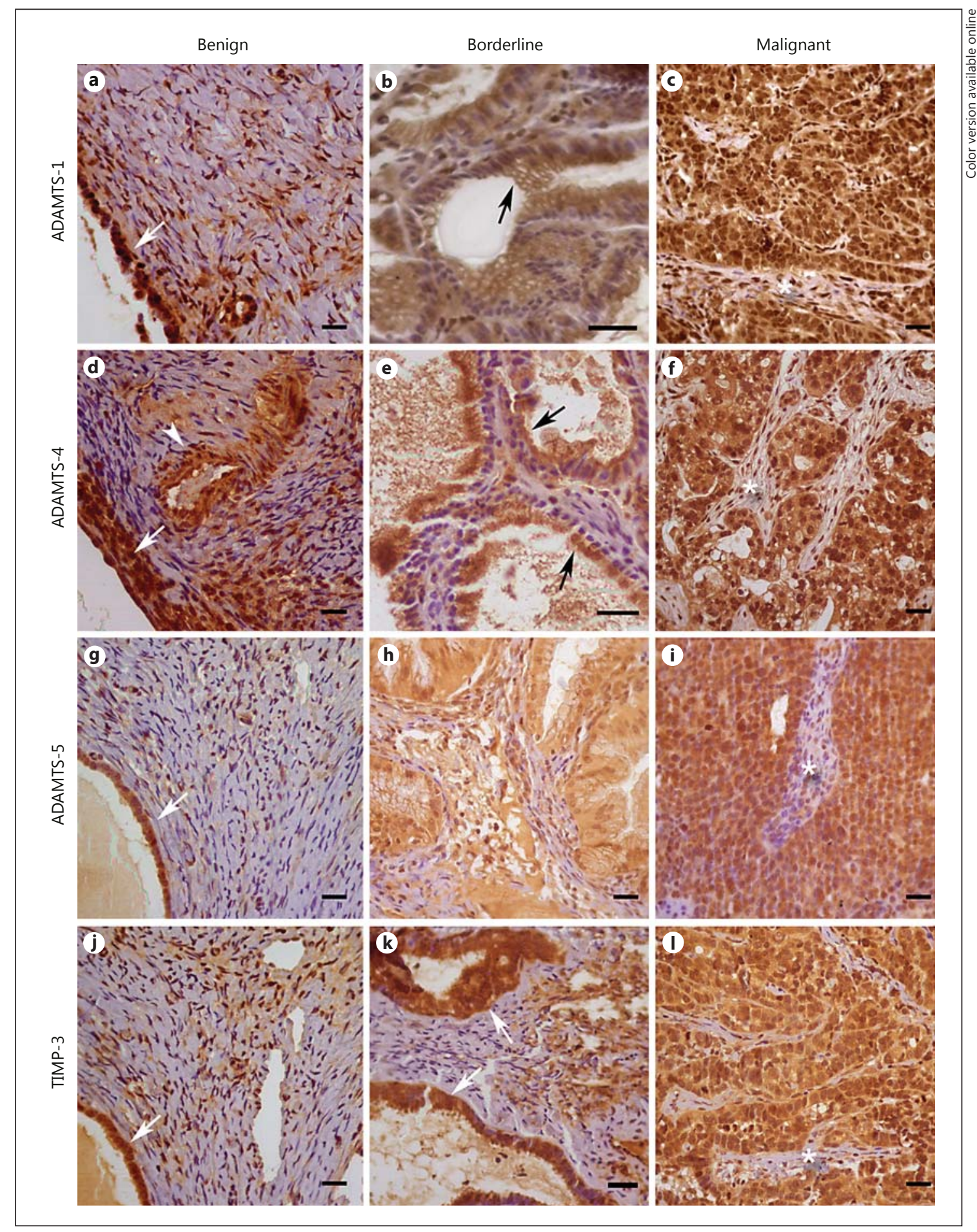

Fig. 1. Immunohistochemical staining of ADAMTS-1, -4, and -5, and TIMP-3 in epithelial ovarian tumor samples. ADAMTS-1, -4 and -5 , and TIMP-3 were present in epithelial cells in benign samples (a, d, g, j; arrows); ADAMTS-4 was also found in the vessel wall (d; arrowhead). Borderline tumors presented cell membrane staining of ADAMTS-1 (b; arrow) and ADAMTS-4 in the apical region of cells (e, arrows). ADAMTS-5 (h) and TIMP-3 (k; arrows) were present in epithelial and stromal cells from borderline tumors. Stroma of malignant tumors showed weak staining for all proteins compared to tumor cells (c, $\mathbf{f}, \mathbf{i}, \mathbf{I}$; asterisks). Scales bars = $50 \mu \mathrm{m}$. 


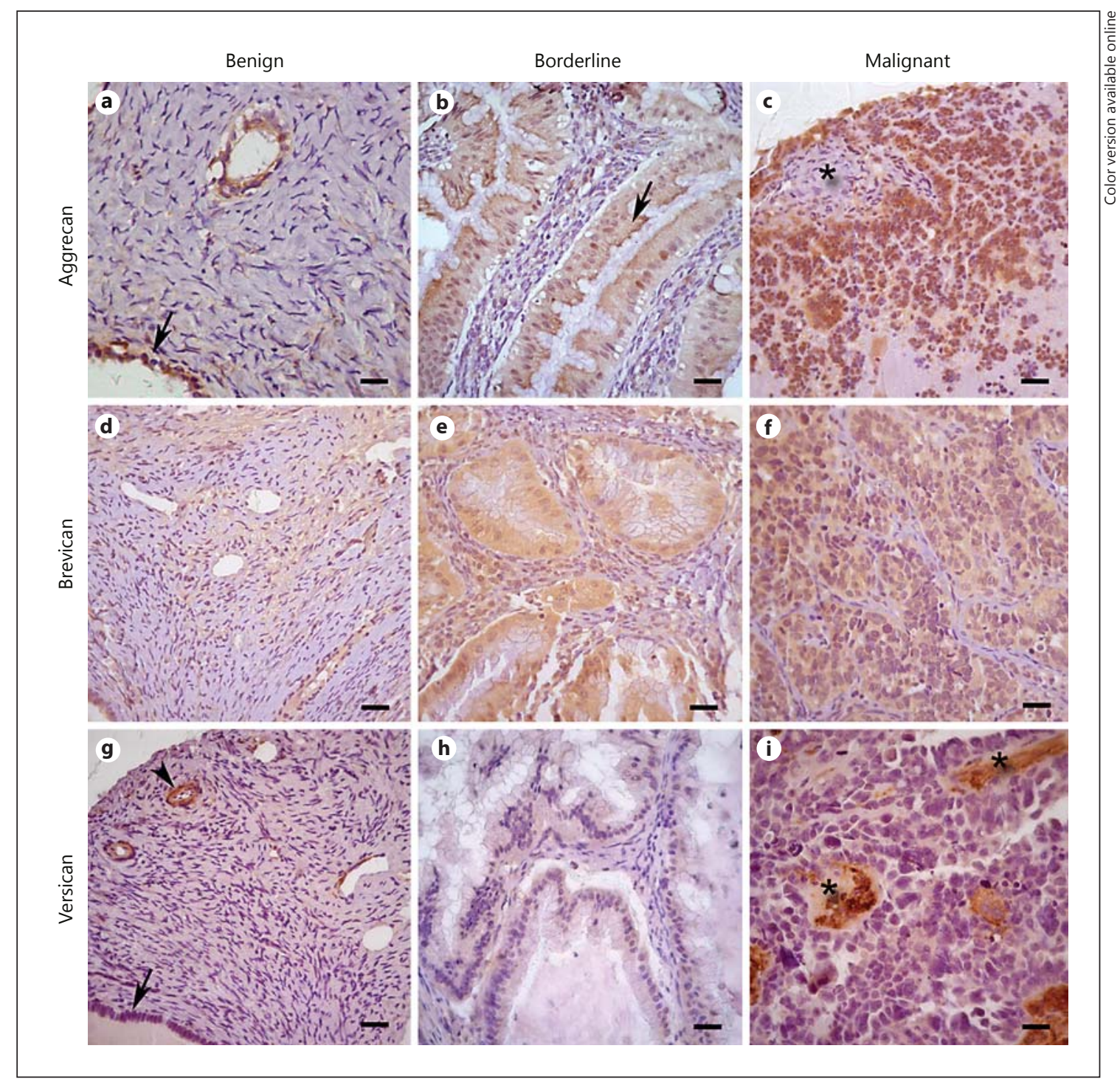

Fig. 2. Immunohistochemical staining of aggrecan, brevican, and versican in epithelial ovarian tumor samples. Aggrecan was present in epithelial cells in benign samples (a; arrow) and in the apical cell region of borderline tumors (b; arrow). In tumor cells of the malignant sample, stroma exhibits faint staining for aggrecan (c; asterisk). There was week immunostaining of brevican in benign (d), borderline (e), and malignant (f) tumors. Versican staining was absent in epithelial cells of benign ( $\mathbf{g}$; arrow) or borderline tumors (h). There was strong labeling of versican in the vessel wall in benign tumors ( $\mathbf{g}$; arrowhead) and deposits of versican in the stroma of malignant tumors (i; asterisks). Scales bars $=50 \mu \mathrm{m}$. that ADAMTS and TIMP-3 expression was significantly increased, with no significant differences in the other substrates studied.

Protease ADAMTS-1 levels were increased in malignant compared to benign tumors. There are few studies on the expression of ADAMTS-1 in tumors in the literature. There are few contributions on ADAMTS in ovarian cancer in the literature. According to de Arao Tan et al. [9], ADAMTS-1 is downregulated in ovarian cancer com- pared to normal tissue. Overexpression of the ADAMTS-1 C-terminal fragment DPM-1 in CHO cells induced tumors with a marked decrease in metastatic activity in nude mice. This inhibitory effect may be related to a lower number of blood vessels. Furthermore, expression of full-length ADAMTS-1 reversed this inhibition of metastatic activity [57]. Using genomic and clinical data, a recent ovarian cancer study showed that somatic mutations in ADAMTS may result in better outcome in ovarian can- 
cer cases and may have important clinical implications [23].

ADAMTS-1, -4 , and -5 are well-known aggrecanases [15-18]. The role of ADAMTS-4 and -5 in rheumatoid arthritis has been well described. In cancer, there are few reports on the function of ADAMTS-4 and -5. Our results revealed no difference in ADAMTS-4 expression among ovarian cancer subtypes. The staining pattern of borderline tumors was interesting, since it was on the apical region of tumors cells. This localization is corroborated by the fact that the spacer domain of ADAMTS-4 interacts with cell surface and pericellular PG [58]. ADAMTS-5 showed increased expression in ovarian malignant tu- mors. It has been associated with human glioblastoma, where ADAMTS-5 is upregulated compared to normal brain tissue, where brevican, one of the ADAMTS- 5 substrates, is abundant $[42,54]$. On the other hand, Kumar et al. [59] reported an antitumorigenic role of ADAMTS-5 in melanoma, which was related to its antiangiogenic properties and was independent of its proteoglycanase activity.

TIMP-3 levels were increased in malignant tumors when compared to borderline and benign neoplasms. TIMP-3 was localized in tumor cell cytoplasm, as previously described for renal, pancreatic, and esophageal tumors [22]. Despite its known inhibitory protease activity,
Fig. 3. Comparisons of total area fractions in benign, borderline, and malignant ovarian cancer (a) and total area fractions of proteases, TIMP-3, and PGs in malignant tumors (b). ${ }^{*} \mathrm{p}<0.05 ;{ }^{* *} \mathrm{p}<0.01 ;{ }^{* *} \mathrm{p}<$ 0.001 .

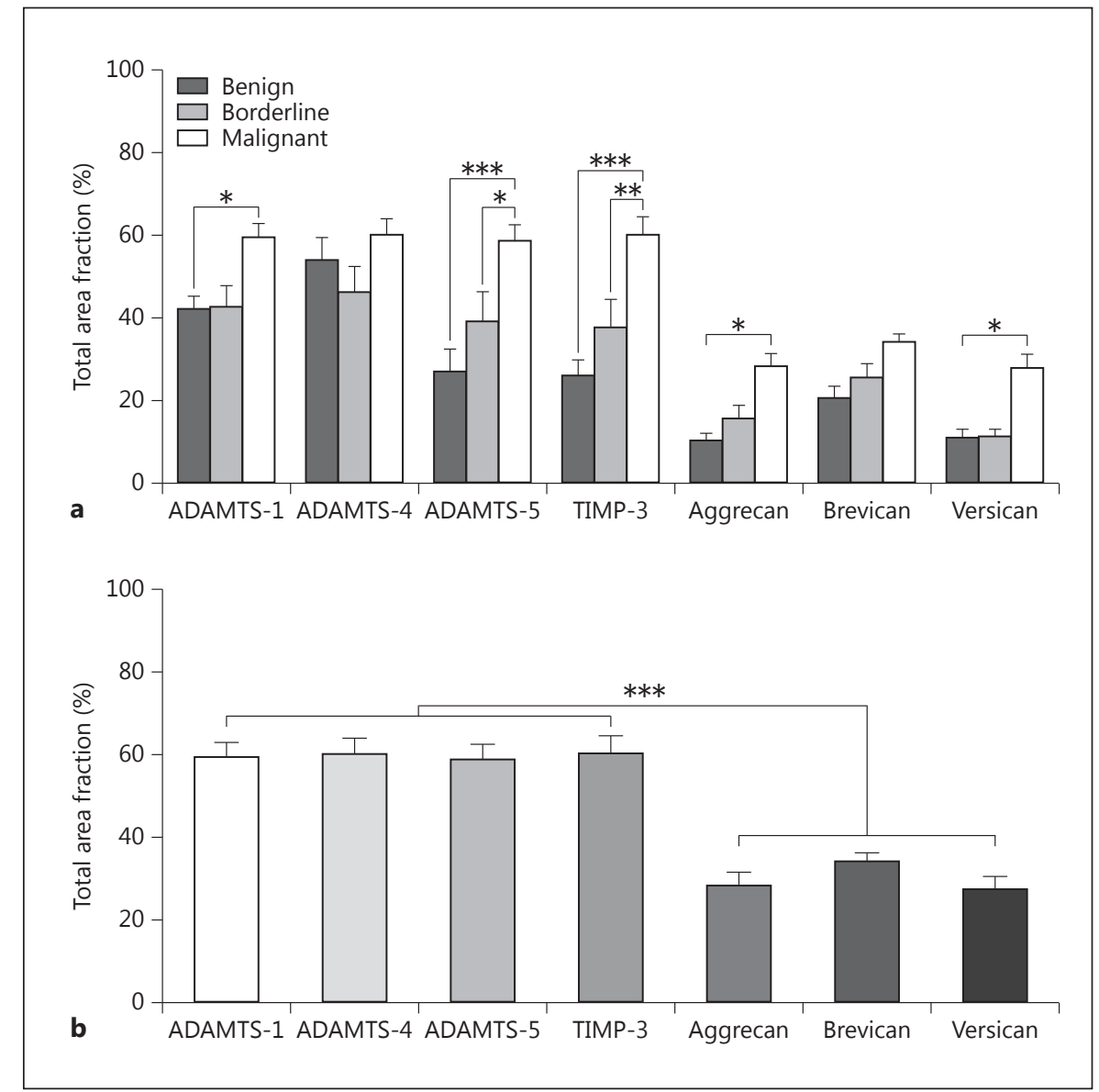

Fig. 4. Increased expression levels of ADAMTS-1 (a), TIMP-3 (d), and versican $(\mathbf{g})$ are associated with decreased overall survival. The overall survival of patients was compared with the protein total area fraction labeling for each of the molecules analyzed. Overall survival in patients with high ADAMTS-1, TIMP-3, and versican was significantly lower than in patients with low expression of these molecules $(\mathbf{a}, \mathbf{d}, \mathbf{g})$. There were no statistically significant differences in ADAMTS-4 (b), ADAMTS-5 (c), aggrecan (e), and brevican (f). p $<0.05$ was considered statistically significant.

(For figure see next page.) 

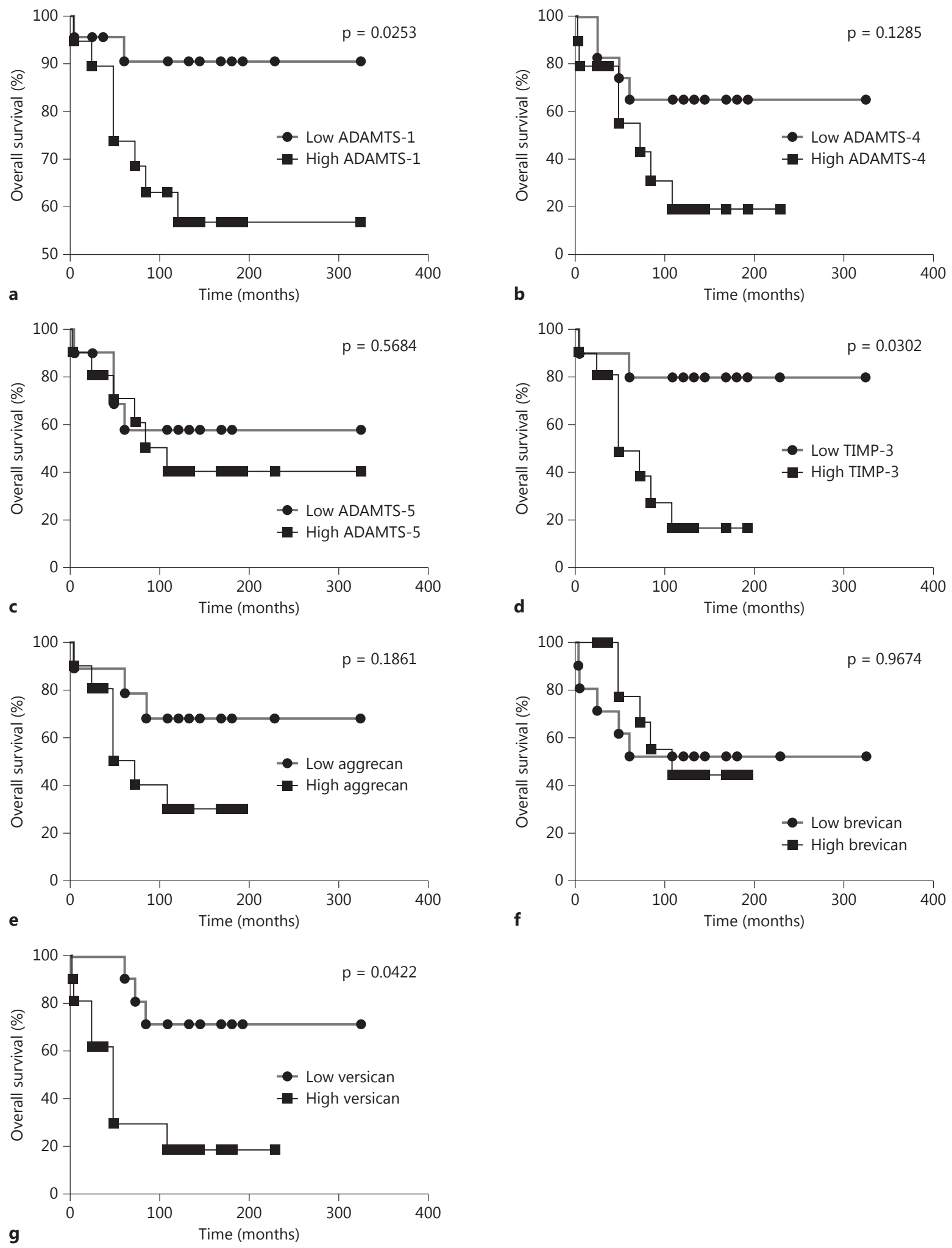
increased TIMP-3 expression was associated with headand-neck tumor development and progression [60]. Activity of aggrecanases is inhibited by TIMP-3. The balance between the activity of ADAMTS-1, -4 and -5 , and TIMP3 controls PG remodeling. In our ovarian cancer cases, levels of ADAMTS as well as levels of their inhibitor TIMP-3 were increased. Since we evaluated only ADAMTS expression and localization, and not activity, it is difficult to state if TIMP-3 is efficiently inhibiting the proteolytic function of ADAMTS. Considering malignant tumors only, we observed that the total areas of protease and TIMP-3 staining were twofold higher than those of aggrecan, brevican, and versican. This evidence leads us to speculate that the proteases are actively involved in PG cleavage in ovarian cancer.

ECM PG affect cancer cell signaling, growth, survival, cell adhesion, migration, and angiogenesis [13]. Here, we observed that aggrecan and versican expression was increased in malignant ovarian cancer compared to benign and borderline neoplasms. In ovarian cancer, brevican expression was not statistically different among groups. Therefore, brevican may possibly play a limited role in ovarian cancer. On the other hand, this PG is a major player in brain tumors [59].

Aggrecan is a high-molecular-weight PG with chondroitin sulfate and keratan sulfate chains attached to a protein core. Aggrecan has two globular structural domains at the N-terminus (G1 and G2) and one globular domain at the C-terminus (G3). Aggrecan binds to HA through G1 subdomains B-B' [61]. ECM molecules, including versican and $\mathrm{HA}$, which interact with the HA receptor, CD44, have been shown to play a critical role in ovarian cancer metastasis [5].

We noted increased versican expression in malignant tumors. Versican has been found in most malignancies to date, including melanomas, as well as prostate, breast, and ovarian tumors. Versican is involved in decreased cell-cell and cell-matrix adhesion, thus facilitating local cancer cell invasion and metastatic spread, which results in a poor outcome $[4,5,62]$.

ADAMTS-1, TIMP-3, and versican protein expression correlates with the patients' overall survival. Patients with low tumor levels of TIMP-3 and versican survived $60 \%$ longer in comparison with patients with a high expression of these two proteins. An independent dataset and online tool [63] were employed to determine the association of ADAMTS-1, TIMP-3, and versican with ovarian cancer outcome (overall survival in 1,307 patients). Overall survival was reduced when ADAMTS-1, TIMP-3, and versican genes presented high expression, corroborating our protein expression results.

Expression of ADAMTS and TIMP-3 was higher than PG expression in malignant tumors. Based on this result, we can speculate that even in the presence of high levels of TIMP-3, these proteases are actively cleaving extracellular PG, thus releasing entrapped growth factors and soluble components that may influence tumor cell behavior.

\section{Acknowledgments}

This work was supported by the State of São Paulo Research Foundation (FAPESP grant 2010/07699-1). Maíra Assis Lima was a recipient of a graduate fellowship from FAPESP (2013/01092-6) and Liliane dos Santos was a recipient of an undergraduate fellowship from PIBIC/CNPq.

\section{Disclosure Statement}

The authors have no conflicts of interest.

\section{References}

1 Chen VW, Ruiz B, Killeen JL, Cote TR, Wu $\mathrm{XC}$, Correa CN: Pathology and classification of ovarian tumors. Cancer 2003;97:26312642.

2 Kurman RJ, Carcangiu ML, Herrington CS, Young RH: WHO Classification of Tumours of Female Reproductive Organs. WHO/IARC Classification of Tumours, ed 4. Lyon, IARC, 2015, vol 6, p 307.

3 Loizzi V, Selvaggi L, Leone L, et al: Borderline epithelial tumors of the ovary: experience of 55 patients. Oncol Lett 2015;9:912-914.
4 Ricciardelli C, Rodgers RJ: Extracellular matrix of ovarian tumors. Semin Reprod Med 2006;24:270-282

5 Ween MP, Oehler MK, Ricciardelli C: Role of versican, hyaluronan and CD44 in ovarian cancer metastasis. Int J Mol Sci 2011;12:10091029.

6 Porter S, Clark IM, Kevorkian L, Edwards DR: The ADAMTS metalloproteinases. Biochem J 2005;386:15-27.

7 Wen J, Zhu H, Leung PC: Gonadal steroids regulate the expression of aggrecanases in human endometrial stromal cells in vitro. J Cell Mol Med 2013;17:1325-1334.
8 Kuno K, Iizasa H, Ohno S, Matsushima K The exon/intron organization and chromosomal mapping of the mouse ADAMTS-1 gene encoding an ADAM family protein with TSP motifs. Genomics 1997;46:466-471.

9 de Arao Tan I, Ricciardelli C, Russell DL: The metalloproteinase ADAMTS1: a comprehensive review of its role in tumorigenic and metastatic pathways. Int J Cancer 2013;133:22632276.

10 Apte SS: A disintegrin-like and metalloprotease (reprolysin type) with thrombospondin type 1 motifs: the ADAMTS family. Int J Biochem Cell Biol 2004;36:981-985. 
11 Wagstaff L, Kelwick R, Decock J, Edwards DR: The roles of ADAMTS metalloproteinases in tumorigenesis and metastasis. Front Biosci 2011;16:1861-1872.

12 Tortorella MD, Malfait F, Barve RA, Shieh HS, Malfait AM: A review of the ADAMTS family, pharmaceutical targets of the future. Curr Pharm Des 2009;15:2359-2374.

13 Theocharis AD, Skandalis SS, Tzanakakis GN, Karamanos NK: Proteoglycans in health and disease: novel roles for proteoglycans in malignancy and their pharmacological targeting. FEBS J 2010;277:3904-3923.

14 Suhovskih AV, Mostovich LA, Kunin IS, et al: Proteoglycan expression in normal human prostate tissue and prostate cancer. ISRN Oncol 2013;2013:680136.

15 Fushimi K, Troeberg L, Nakamura H, Lim $\mathrm{NH}$, Nagase H: Functional differences of the catalytic and non-catalytic domains in human ADAMTS-4 and ADAMTS-5 in aggrecanolytic activity. J Biol Chem 2008;283:67066716.

16 Gendron C, Kashiwagi M, Lim NH, et al: Proteolytic activities of human ADAMTS-5: comparative studies with ADAMTS-4. J Biol Chem 2007;282:18294-18306.

17 Rodriguez-Manzaneque JC, Westling J, Thai $\mathrm{SN}$, et al: ADAMTS1 cleaves aggrecan at multiple sites and is differentially inhibited by metalloproteinase inhibitors. Biochem Biophys Res Commun 2002;293:501-508.

18 Stanton H, Melrose J, Little CB, Fosang AJ: Proteoglycan degradation by the ADAMTS family of proteinases. Biochim Biophys Acta 2011;1812:1616-1629.

19 Iozzo RV: Matrix proteoglycans: from molecular design to cellular function. Annu Rev Biochem 1998;67:609-652.

20 Lambert E, Dasse E, Haye B, Petitfrere E: TIMPs as multifacial proteins. Crit Rev Oncol Hematol 2004;49:187-198.

21 Nagase H, Visse R, Murphy G: Structure and function of matrix metalloproteinases and TIMPs. Cardiovasc Res 2006;69:562-573.

22 Turner SL, Mangnall D, Bird NC, Bunning RA, Blair-Zajdel ME: Expression of ADAMTS-1, ADAMTS-4, ADAMTS-5 and TIMP3 by hepatocellular carcinoma cell lines. Int J Oncol 2012;41:1043-1049.

23 Liu Y, Yasukawa M, Chen K, et al: Association of somatic mutations of ADAMTS genes with chemotherapy sensitivity and survival in high-grade serous ovarian carcinoma. JAMA Oncol 2015;1:486-494.

24 Mittaz L, Russell DL, Wilson T, et al: Adamts- 1 is essential for the development and function of the urogenital system. Biol Reprod 2004;70:1096-1105.

25 Freitas VM, do Amaral JB, Silva TA, et al: Decreased expression of ADAMTS-1 in human breast tumors stimulates migration and invasion. Mol Cancer 2013;12:2.
26 Shindo T, Kurihara H, Kuno K, et al: ADAMTS-1: a metalloproteinase-disintegrin essential for normal growth, fertility, and organ morphology and function. J Clin Invest 2000; 105:1345-1352.

27 Sandy JD, Westling J, Kenagy RD, et al: Versican $\mathrm{V} 1$ proteolysis in human aorta in vivo occurs at the Glu441-Ala442 bond, a site that is cleaved by recombinant ADAMTS- 1 and ADAMTS-4. J Biol Chem 2001;276:1337213378.

28 Shozu M, Minami N, Yokoyama $\mathrm{H}$, et al: ADAMTS- 1 is involved in normal follicular development, ovulatory process and organization of the medullary vascular network in the ovary. J Mol Endocrinol 2005;35:343-355.

29 Brown HM, Dunning KR, Robker RL, et al: ADAMTS1 cleavage of versican mediates essential structural remodeling of the ovarian follicle and cumulus-oocyte matrix during ovulation in mice. Biol Reprod 2010;83:549557.

30 Brown HM, Dunning KR, Robker RL, Pritchard M, Russell DL: Requirement for ADAMTS-1 in extracellular matrix remodeling during ovarian folliculogenesis and lymphangiogenesis. Dev Biol 2006;300:699-709.

31 Torres-Collado AX, Kisiel W, Iruela-Arispe ML, Rodríguez-Manzaneque JC: ADAMTS1 interacts with, cleaves, and modifies the extracellular location of the matrix inhibitor tissue factor pathway inhibitor-2. J Biol Chem 2006; 281:17827-17837.

32 Mishra B, Koshi K, Kizaki K, et al: Expression of ADAMTS1 mRNA in bovine endometrium and placenta during gestation. Domest Anim Endocrinol 2013;45:43-48.

33 Jönsson-Rylander AC, Nilsson T, FritscheDanielson R, et al: Role of ADAMTS-1 in atherosclerosis: remodeling of carotid artery, immunohistochemistry, and proteolysis of versican. Arterioscler Thromb Vasc Biol 2005; 25:180-185.

34 Lee NV, Sato M, Annis DS, et al: ADAMTS1 mediates the release of antiangiogenic polypeptides from TSP1 and 2. EMBO J 2006;25: 5270-5283.

35 Miguel RF, Pollak A, Lubec G: Metalloproteinase ADAMTS- 1 but not ADAMTS- 5 is manifold overexpressed in neurodegenerative disorders as Down syndrome, Alzheimer's and Pick's disease. Brain Res Mol Brain Res 2005; 133:1-5.

36 Naito S, Shiomi T, Okada A, et al: Expression of ADAMTS4 (aggrecanase-1) in human osteoarthritic cartilage. Pathol Int 2007;57:703711.

37 Yamanishi Y, Boyle DL, Clark M, et al: Expression and regulation of aggrecanase in arthritis: the role of TGF-beta. J Immunol 2002; 168:1405-1412.

38 Verma P, Dalal K: ADAMTS-4 and ADAMTS-5: key enzymes in osteoarthritis. J Cell Biochem 2011;112:3507-3514.
39 Westling J, Gottschall PE, Thompson VP, et al: ADAMTS4 (aggrecanase-1) cleaves human brain versican V2 at Glu405-Gln406 to generate glial hyaluronate binding protein. Biochem J 2004;377:787-795.

40 Madan P, Bridges PJ, Komar CM, et al: Expression of messenger RNA for ADAMTS subtypes changes in the periovulatory follicle after the gonadotropin surge and during luteal development and regression in cattle. Biol Reprod 2003;69:1506-1514.

41 Richards JS, Hernandez-Gonzalez I, Gonzalez-Robayna I, et al: Regulated expression of ADAMTS family members in follicles and cumulus oocyte complexes: evidence for specific and redundant patterns during ovulation. Biol Reprod 2005;72:1241-1255.

42 Held-Feindt J, Paredes EB, Blomer U, et al: Matrix-degrading proteases ADAMTS4 and ADAMTS5 (disintegrins and metalloproteinases with thrombospondin motifs 4 and 5) are expressed in human glioblastomas. Int J Cancer 2006;118:55-61.

43 Matthews RT, Gary SC, Zerillo C, et al: Brainenriched hyaluronan binding (BEHAB)/ brevican cleavage in a glioma cell line is mediated by a disintegrin and metalloproteinase with thrombospondin motifs (ADAMTS) family member. J Biol Chem 2000;275:2269522703.

44 Tauchi R, Imagama S, Natori $T$, et al: The endogenous proteoglycan-degrading enzyme ADAMTS-4 promotes functional recovery after spinal cord injury. J Neuroinflammation 2012;9:53.

45 Ashlin TG, Kwan AP, Ramji DP: Regulation of ADAMTS-1, - 4 and -5 expression in human macrophages: differential regulation by key cytokines implicated in atherosclerosis and novel synergism between TL1A and IL17. Cytokine 2013;64:234-242.

46 Ehlen HW, Sengle G, Klatt AR, et al: Proteolytic processing causes extensive heterogeneity of tissue matrilin forms. J Biol Chem 2009; 284:21545-21556.

47 Monfort J, Tardif G, Reboul P, et al: Degradation of small leucine-rich repeat proteoglycans by matrix metalloprotease-13: identification of a new biglycan cleavage site. Arthritis Res Ther 2006;8:R26.

48 Melching LI, Fisher WD, Lee ER, Mort JS, Roughley PJ: The cleavage of biglycan by aggrecanases. Osteoarthritis Cartilage 2006;14: 1147-1154.

49 Plaas A, Osborn B, Yoshihara Y, et al: Aggrecanolysis in human osteoarthritis: confocal localization and biochemical characterization of ADAMTS5-hyaluronan complexes in articular cartilages. Osteoarthritis Cartilage 2007;15:719-734.

50 Abbaszade I, Liu RQ, Yang F, et al: Cloning and characterization of ADAMTS11, an aggrecanase from the ADAMTS family. J Biol Chem 1999;274:23443-23450. 
51 Djouad F, Delorme B, Maurice M, et al: Microenvironmental changes during differentiation of mesenchymal stem cells towards chondrocytes. Arthritis Res Ther 2007;9: R33.

52 Longpré JM, McCulloch DR, Koo BH, Alexander JP, Apte SS, Leduc R: Characterization of proADAMTS5 processing by proprotein convertases. Int J Biochem Cell Biol 2009;41: $1116-1126$

53 Hurskainen TL, Hirohata S, Seldin MF, Apte SS: ADAM-TS5, ADAM-TS6, and ADAMTS7, novel members of a new family of zinc metalloproteases. General features and genomic distribution of the ADAM-TS family. J Biol Chem 1999;274:25555-25563.

54 Nakada M, Miyamori H, Kita D, et al: Human glioblastomas overexpress ADAMTS-5 that degrades brevican. Acta Neuropathol 2005; 110:239-246.

55 Cross NA, Chandrasekharan S, Jokonya N, et al: The expression and regulation of $\mathrm{AD}$ AMTS- $1,-4,-5,-9$, and -15 , and TIMP- 3 by
TGF $\beta 1$ in prostate cells: relevance to the accumulation of versican. Prostate 2005;63: 269-275.

56 Groma G, Grskovic I, Schael S, et al: Matrilin- 4 is processed by ADAMTS- 5 in late Golgi vesicles present in growth plate chondrocytes of defined differentiation state. Matrix Biol 2011;30:275-280.

57 Kuno K, Bannai K, Hakozaki M, Matsushima $\mathrm{K}$, Hirose K: The carboxyl-terminal half region of ADAMTS-1 suppresses both tumorigenicity and experimental tumor metastatic potential. Biochem Biophys Res Commun 2004;319:1327-1333.

58 Gao G, Plaas A, Thompson VP, Jin S, Zuo F, Sandy JD: ADAMTS4 (aggrecanase-1) activation on the cell surface involves C-terminal cleavage by glycosylphosphatidyl inositol-anchored membrane type 4-matrix metalloproteinase and binding of the activated proteinase to chondroitin sulfate and heparan sulfate on syndecan-1. J Biol Chem 2004;279:1004210051.
59 Kumar S, Sharghi-Namini S, Rao N, Ge R: ADAMTS5 functions as an anti-angiogenic and anti-tumorigenic protein independent of its proteoglycanase activity. Am J Pathol 2012;181:1056-1068.

60 Kornfeld JW, Meder S, Wohlberg M, et al: Overexpression of TACE and TIMP3 mRNA in head and neck cancer: association with tumour development and progression. $\mathrm{Br} \mathrm{J}$ Cancer 2011;104:138-145.

61 Watanabe H, Cheung SC, Itano N, Kimata $\mathrm{K}$, Yamada Y: Identification of hyaluronanbinding domains of aggrecan. J Biol Chem 1997;272:28057-28065.

62 Voutilainen K, Anttila M, Sillanpaa S, et al: Versican in epithelial ovarian cancer: relation to hyaluronan, clinicopathologic factors and prognosis. Int J Cancer 2003;107:359-364.

63 Gyorffy B, Lanczky A, Szallasi Z: Implementing an online tool for genome-wide validation of survival-associated biomarkers in ovarian cancer using microarray data of 1,287 patients. Endocr Relat Cancer 2012;19:197-208. 